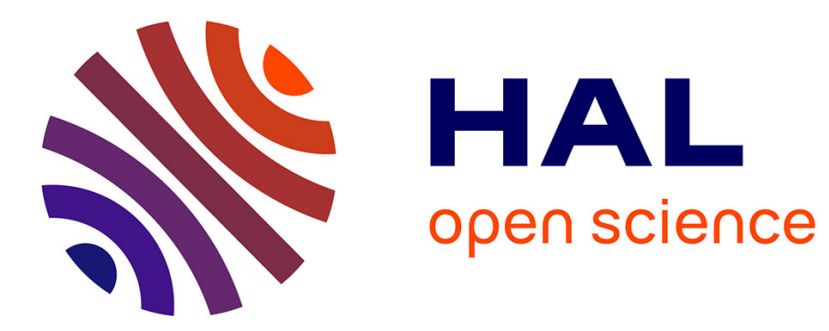

\title{
Essential role for the homeoprotein vHNF1/HNF1beta in visceral endoderm differentiation.
}

Catherine Coffinier, Dominique Thepot Thépot, C Babinet, M Yaniv, J Barra

\section{To cite this version:}

Catherine Coffinier, Dominique Thepot Thépot, C Babinet, M Yaniv, J Barra. Essential role for the homeoprotein vHNF1/HNF1beta in visceral endoderm differentiation.. Development (Cambridge, England), 1999, 126 (21), pp.4785-94. hal-02690542

\section{HAL Id: hal-02690542 \\ https://hal.inrae.fr/hal-02690542}

Submitted on 1 Jun 2020

HAL is a multi-disciplinary open access archive for the deposit and dissemination of scientific research documents, whether they are published or not. The documents may come from teaching and research institutions in France or abroad, or from public or private research centers.
L'archive ouverte pluridisciplinaire HAL, est destinée au dépôt et à la diffusion de documents scientifiques de niveau recherche, publiés ou non, émanant des établissements d'enseignement et de recherche français ou étrangers, des laboratoires publics ou privés. 


\title{
Essential role for the homeoprotein vHNF1/HNF1 $\beta$ in visceral endoderm
}

\section{differentiation}

\author{
Catherine Coffinier ${ }^{1}$, Dominique Thépot ${ }^{1, *}$, Charles Babinet ${ }^{2}$, Moshe Yaniv ${ }^{1, \ddagger}$ and Jacqueline Barra ${ }^{2}$ \\ 1 Unité des Virus Oncogènes, CNRS URA 1644, and 2Unité de Biologie du Développement, CNRS URA 1960, Institut Pasteur, 25 \\ rue du Dr Roux, F-75724 Paris Cedex 15, France \\ *Present address: Laboratoire de Biologie Cellulaire et Moléculaire, Unité de Différenciation Cellulaire, INRA, F-78352 Jouy en Josas, France \\ ‡Author for correspondence (e-mail: yaniv@pasteur.fr)
}

Accepted 26 July; published on WWW 6 October 1999

\section{SUMMARY}

$v H N F 1 / H N F 1 \beta$, a member of the divergent HNF1/vHNF1 homeoprotein family, is expressed in polarized epithelia of several adult organs and may participate in controlling the transcription of specific genes. In addition to this late requirement, $v H N F 1$ may play earlier roles during development, as it is first expressed in the visceral endoderm at the onset of gastrulation. In order to shed light on its function during embryogenesis, we have inactivated the murine gene by homologous recombination. The homozygous mutation results in embryonic lethality by day 7.5 of development and $\mathrm{vHNF}^{-1-}$ embryos display a disorganized visceral endoderm and a significantly reduced size. Studies of ES cell differentiation and aggregation with tetraploid morulae establish that $v H N F 1$ expression is essential for visceral endoderm differentiation, both in vitro and in vivo. Analysis of differentiation markers confirms that $v H N F 1$ is part of a genetic network that directs the expression of HNF4 and downstream endodermal genes. Furthermore, the complementation of the mutant embryos with wild-type visceral endoderm rescues the day 7.5 lethality and reveals an additional phenotype linked to $v H N F 1$ later expression. The examination of chimeric embryos suggests that $v H N F 1$ expression might be cell-autonomously required in the gut for the proper morphogenesis of the embryo.

Key words: Visceral endoderm, Embryonic lethality, Tetraploid rescue, Homeoprotein, Gene knock-out.

\section{INTRODUCTION}

A surprisingly limited number of steps during mouse development are essential for the survival of the embryo (Copp, 1995). Early embryonic lethality is frequently observed when the interactions between the mother and the embryo are perturbed. For example, the inactivation of genes encoding for Mash-2 or Ets-2 results in embryonic failure due to an impaired trophoblastic function (Guillemot et al., 1994; Yamamoto et al., 1998). Differentiation of the visceral endoderm is another important step of embryonic development. The visceral endoderm plays a crucial role by supporting the metabolism and the growth of the embryo. In addition, its anterior territory has recently been shown to function as an organizer for head structures (Beddington and Robertson, 1998). A number of transcription factors are known to be specifically expressed in the visceral endoderm around gastrulation, among them HNF3 $\beta$ and HNF4 $\alpha$ (Duncan et al., 1994; Monaghan et al., 1993; Taraviras et al., 1994). For both HNF3 $\beta$ and HNF4 $\alpha$ mutations, a defect in the visceral endoderm has been suggested (Ang and Rossant, 1994; Chen et al., 1994; Weinstein et al., 1994). These mutations lead to embryonic lethality between days 8.5 and 10.5 of development. $H N F 3 \beta$ expression in the anterior visceral endoderm is important for the patterning of the anteroposterior axis (Dufort et al., 1998), while $H N F 4 \alpha$ is involved in regulating the metabolic functions of extraembryonic visceral endoderm (Duncan et al., 1998).

Interestingly, HNF3 and HNF4 were initially characterized as liver-enriched transcription factors. Indeed, the liver and the visceral endoderm perform several equivalent functions, such as protein secretion and metabolite absorption; they also share an important number of differentiation markers (Meehan et al., 1984). Hence, it is plausible that, in addition to HNF3 and HNF4, other classes of Hepatocyte Nuclear Factors could be involved in visceral endoderm differentiation. Good candidates included the two closely related atypical homeoproteins, HNF1 and vHNF1 (also named HNF1 $\alpha$ and HNF1 $\beta$, respectively). These factors bind to identical DNA sequences, as either homodimers or heterodimers (Tronche and Yaniv, 1992). $\checkmark H N F 1$ mRNA is detectable in the visceral endoderm from early developmental stages, while $H N F 1$ is first expressed in the yolk sac and in the liver bud (Blumenfeld et al., 1991; Cereghini et al., 1992). Later on, they are expressed throughout organogenesis of the liver, the kidney and the pancreas where their expression is maintained up to the adult stage. Still, HNF 1 and $v H N F 1$ display some specificity: for instance, $v H N F 1$ and not HNF1 is expressed in the lungs (Cereghini et al., 1992; Ott et al., 1991). This suggests the existence of specific targets for 
each gene, and indeed $H N F 1$ inactivation has provided the first evidence for the existence of $H N F 1$-specific target genes in these tissues (Pontoglio et al., 1996).

$\mathrm{HNF}^{-/-}$mice develop normally but fail to transcribe several hepatic genes, are defective in renal glucose reabsorption and suffer from type II diabetes (Pontoglio et al., 1998). Since $v H N F 1$ expression precedes HNF1 synthesis, it has been suggested that vHNF1 might compensate for HNF1 function during development; alternatively, HNF1 could be dispensable during embryogenesis. To address these issues, we have performed the inactivation of the $v H N F 1$ gene. $\mathrm{vHNF}^{-1-}$ embryos die around day 7.5 post-coitum (E7.5) at a time where $v H N F 1$ is specifically expressed in the extraembryonic visceral endoderm. The defect in visceral endoderm differentiation can be partially rescued by wild-type visceral endoderm. Further development results in $\mathrm{vHNF} 1^{-I-}$ embryos of a normal size but displaying severe abnormalities.

\section{MATERIALS AND METHODS}

\section{Targeting of the vHNF1 locus}

$v H N F 1$ genomic clones were isolated from a $129 / \mathrm{SvJ}$ mouse phage library. Genomic fragments of $3.3 \mathrm{~kb}$ and $2.2 \mathrm{~kb}$ flanking the first exon were introduced into the recombination vector pPNT (Tybulewicz et al., 1991). A NLS-lacZ cassette, described by Pontoglio et al. (1996), was introduced at the initiation codon of $v H N F 1$ into a $N c o$ I site generated using the primers: 5'-GTCCAAAGGTACCCTAAAGTTTGG-3' and 5'-CTTGGACACGGTCCAAGGACG-3'. CK35 ES cells (Kress et al., 1998) were electroporated with the NotI-linearized vector as described by Pontoglio et al. (1996). G418-resistant clones were analyzed by Southern blot after $X b a \mathrm{I}$ digestion using a EcoRIFokI 5' external probe and a BamHI-EcoRI 3' external probe. Singlecopy integration was verified using a PstI neo probe. ES cell injections into blastocysts were accomplished as previously described (Pontoglio et al., 1996).

\section{Mouse and ES cell DNA analysis}

DNA from either mouse tails or ES cells was directly precipitated with isopropanol after proteinase $\mathrm{K}$ treatment. A three-way PCR was performed with a sense primer hybridizing to the $v H N F 1$ promoter $\left(5^{\prime}\right.$ CCCAACTTGTCCAGCTCTCTCACC-3') and two reverse primers in the $v H N F 1$ first exon (5'-CTGAGCATCCGGTCCACCTCG-3') and in the lac $Z$ gene (5'-GGGAAGGGCGATCGGTGCGG-3') generating respectively a wild-type 900 bp band and a mutant $v H N F 1 /$ acZ 800 bp band (arrows in Fig. 1A).

\section{X-gal staining and histological analysis}

Embryos were collected at different gestation times, plugs in the morning being counted as day 0.5 post-coitum (E0.5). Embryos were fixed for 10 minutes in $4 \%$ paraformaldehyde and abundantly washed in PBS. Whole-mount X-gal staining was performed overnight as described by Pontoglio et al. (1996). Genotyping of the embryos was made using the three-way PCR described above, on DNA isolated from ectoplacental cones cultured for 1 week in microwells with DMEM 10\% FCS (Ang and Rossant, 1994). Historesin (Leica)embedded embryos were thin-sectioned with a microtome and counterstained with Safranine.

\section{Homozygous ES cells generation and embryoid body culture}

$\mathrm{vHNF} 1 /$ lac $Z^{-1-}$ ES cells were isolated from $\mathrm{vHNF} 1 / \mathrm{lac} \mathrm{Z}^{+/}$clones by increasing G418 selection (1.5 mg/ml) (Mortensen et al., 1992) and genotyped using PCR. Either $\mathrm{vHNF} 1^{+/+}, \mathrm{vHNF}^{+/-}$or $\mathrm{vHNF}^{-/-} \mathrm{ES}$ cells were mildly trypsinized and put in suspension culture in bacterial plates (Rudnicki and McBurney, 1987). Embryoid bodies (EB) were collected after 14 days culture and stained with SJA lectin (Sophora japonica agglutinin, Sigma) as described by Soudais et al. (1995).

\section{RT-PCR analysis on embryoid bodies and embryos}

Total RNAs were prepared from EB according to Koopman (1993). RT-PCR analysis was performed including [ $\left.{ }^{32} \mathrm{P}\right] \mathrm{dATP}$ incorporation as described by Duncan et al. (1997). Either $1 \mu \mathrm{g}$ from EB RNA or from one wild-type embryo was used per RT reaction; homozygous embryos were pooled as sets of four embryos. The PCR conditions and the primer sequences used for HNF4, HNF1, TFN, TTR, AFP, GATA4, Apo AI and Apo AIV were described by Duncan et al. (1997). The following oligonucleotides were used to detect the expression of $H N F 3 \alpha$ : (5'-GTAGACAGTAGGGGCTC-3', 5'-GGGGAATCCTTTAAACGG-3'); HNF3 $\beta$ : (5'-GCCTGAGCCGCGCTCGGGAC-3',

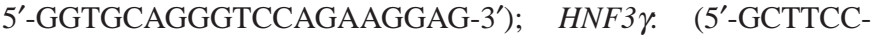
GGGTATGTAGCCCC-3', 5'-GCAAGGCCCAGTAGGAGCC-3'); GATA-6: (5'-CAGCCCACGTTACGATGAACG-3', 5'-AAAATGCAGACATAACATTCC-3'). HPRT primers were used to normalize the RT-PCR reaction (Wiles, 1993) and RT performed without the reverse transcriptase was used as a negative control.

\section{Production of a vHNF1-specific antiserum and western blot analysis}

A GST-fusion protein containing vHNF1 amino acids 321 to 378 was used to immunize rabbits. Immune serum was purified by affinity first on a GST column then on a GST-vHNF1 column. Purified antiserum was tested on nuclear kidney extract and in vitro vHNF1 protein, and recognized specifically a $69 \mathrm{kDa}$ band corresponding to the expected molecular weight of the vHNF1 protein. Western blot analysis was performed with this antiserum using $30 \mu \mathrm{g}$ of total protein extracts from 14-day-old embryoid bodies.

\section{Tetraploid aggregation and chimeras}

Tetraploid embryos were generated from $\mathrm{F}_{1}$ B6/SJL 2-cell embryos using an electric shock to fuse the blastomers. They were cultured in vitro up to the 4-cell stage and then aggregated by pairs of two embryos with a clump of ES cells (Nagy et al., 1993). Resulting blastocysts were reimplanted the following day into the uterus of day 2.5 p.c. pseudopregnant mice. Chimeric embryos were obtained by the injection of 7-8 ES cells into wild-type blastocysts.

\section{RESULTS}

\section{Generation of vHNF1 mutant alleles}

To produce a null allele of the $v H N F 1$ gene and prevent the production of any truncated protein that could interact with HNF1, we chose to delete the first exon of $v H N F 1$ that encodes the dimerization domain. Genomic DNA covering the $5^{\prime}$ regulatory regions and the two first exons of $v H N F 1$ was isolated from a 129/SvJ mouse DNA library. We constructed a recombination vector in which the first exon of $v H N F 1$ was replaced by an NLS-lacZ reporter gene placed at the initiation codon (Fig. 1A). After electroporation into CK35 embryonic stem (ES) cells (Kress et al., 1998) and double selection (neo $t k)$, seven recombinant clones were identified by Southern blot analysis, which contained a vHNF1/lacZ recombinant allele (Fig. 1B). All of them carried a single-copy integration at the locus as revealed by Southern blot analysis with a neo probe (data not shown).

ES cells homozygous for the vHNF1 mutation were isolated from two independent $\mathrm{vHNF}^{+/-}$clones after culture in high G418 concentration (Mortensen et al., 1992). A large majority of the clones isolated had spontaneously replaced the wild-type 


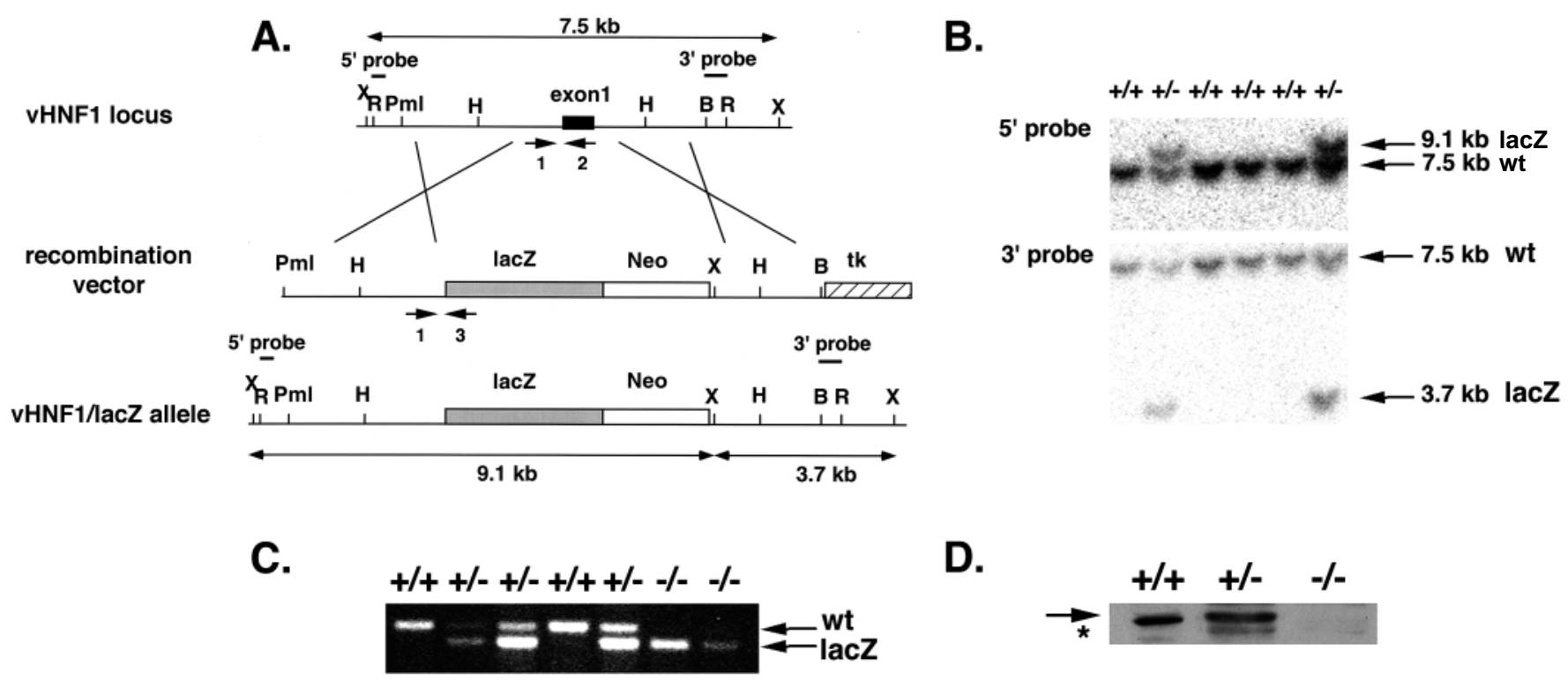

Fig. 1. Targeted inactivation of the murine $v H N F 1$ gene. (A) Strategy used for inactivating the $v H N F 1$ gene by homologous recombination in ES cells. Clone analysis was performed using the $5^{\prime}$ and $3^{\prime}$ probes and $X b a I$ sites, two sites external to the construct and a third site introduced by the recombination. The arrows indicate the positions of the primers used for the PCR analysis of embryos and mice. X, XbaI; R, EcoRI; Pml, PmlI; H, HindIII; B, BamHI. (B) Southern blot analysis of the ES clones isolated after positive-negative selection using the 5' and 3' probes. Two $v H N F 1$ heterozygous (+/-) and four wild-type $(+/+)$ clones are presented. (C) PCR analysis of a litter from $v H N F 1^{+/-}$intercross collected at E7.5, featuring wild-type $(+/+)$, heterozygous $(+/-)$ and homozygous $(-/-)$ embryos. The arrows indicate the bands characteristic of the wild-type (wt) and the vHNF1/lacZ (lacZ) alleles. (D) Western blot analysis of total protein extracts from differentiated vHNF1 ${ }^{+/+}$,

$\mathrm{vHNF} 1^{+/-}$and $\mathrm{vHNF} 1^{-/-}$ES cells using a vHNF1-specific antiserum. The arrow indicates the $69 \mathrm{kDa}$ vHNF1-specific band, and the star, a nonspecific band.

allele by a second vHNF1/lacZ allele, as confirmed using PCR and Southern blot analysis (Fig. 1C; data not shown). As vHNF1 synthesis is induced after in vitro differentiation of ES cells (Abe et al., 1996), western blot analysis was performed on differentiated $\mathrm{vHNF} 1^{+/+}, \mathrm{vHNF} 1^{+/-}$and $\mathrm{vHNF} 1^{-/-} \mathrm{ES}$ cells to confirm that the vHNF1/lacZ allele was indeed a null allele. As shown in Fig. 1D, vHNF1 protein was absent in total protein extracts from differentiated $\mathrm{vHNF} 1^{-/} \mathrm{ES}$ cells. In contrast, a $69 \mathrm{kDa}$ band corresponding to the $\mathrm{vHNF} 1$ protein was detected in the $\mathrm{vHNF} 1^{+/+}$and $\mathrm{vHNF} 1^{+/-}$cell extracts.

A second construct containing three loxP sites flanking the first exon of $v H N F 1$ and the neo cassette was introduced by homologous recombination using the same strategy as for the vHNF1/lacZ construct. After isolation of recombinant clones, ES cells were transiently transfected with the Cre-expressing vector pIC-Cre (Gu et al., 1993) and clones where both the exon and the selection gene have been deleted, were isolated (data not shown). Such a deletion is predicted to result in a null allele as the promoter, the transcription initiation site and the first exon of vHNF1 were all eliminated.

For both the vHNF1/lacZ and the vHNF1/del alleles, one recombinant ES clone was injected into blastocysts; the two alleles were successfully transmitted through germline and gave rise to normal and fertile heterozygous animals. As identical phenotypes were observed for both strains of mice at the homozygous state, only results concerning the $\mathrm{vHNF} 1 /$ lac $Z$ strain are presented here (noted below simply as $\mathrm{vHNF}^{-1-}$ ).

\section{vHNF1/lacZ expression during early development}

Heterozygous mice carrying the vHNF1/lacZ allele were used to follow the expression of $v H N F 1$ during embryonic development by X-gal staining of whole embryos. vHNF1/lacZ was first detected in the visceral endoderm at day 7.5 postcoitum (E7.5) (Fig. 2A). Notably, $\beta$-galactosidase activity was detected exclusively in the extraembryonic part of the visceral endoderm (Figs 2A, 4A); this region is formed of columnar cells and differs morphologically from the squamous epithelium surrounding the embryo. Later on, the extraembryonic visceral endoderm gives rise to the yolk sac endoderm, which also expressed vHNF1/lacZ (Fig. 2B). In addition to this very early expression in extraembryonic tissues, $\mathrm{vHNF} 1 /$ lac $Z$ was detected in the embryo itself from E8. It was visible as early as the 2-somite stage in the neural tube and a few hours later in the invaginating gut (Fig. 2B).

The X-gal staining in the neural tube was very dynamic. It was detected in the central part of the neural folds as early as the 2-somite stage with only scattered nuclei marked (Fig. 2B). As the neural folds merge, the number of positive cells and the intensity of the signal increased very rapidly (Fig. 2C). Concomitantly to the neural tube closure, $\beta$-galactosidase expression became progressively restricted to a sharp stripe at the level of the otic vesicle (Fig. 2D) and to a broader and more posterior domain. Half a day later, only cells of the roof plate and the floor plate are still expressing vHNF1/lacZ in this part of the neural tube as can be seen on sections (data not shown).

vHNF1/lacZ expression starts in the gut epithelium during its invagination. A sharp anterior boundary was observed at E9.5 at the level of the pancreas and liver primordia (Fig. 2D). The expression extended posteriorly to the tip of the gut.

The expression pattern described above was confirmed by 

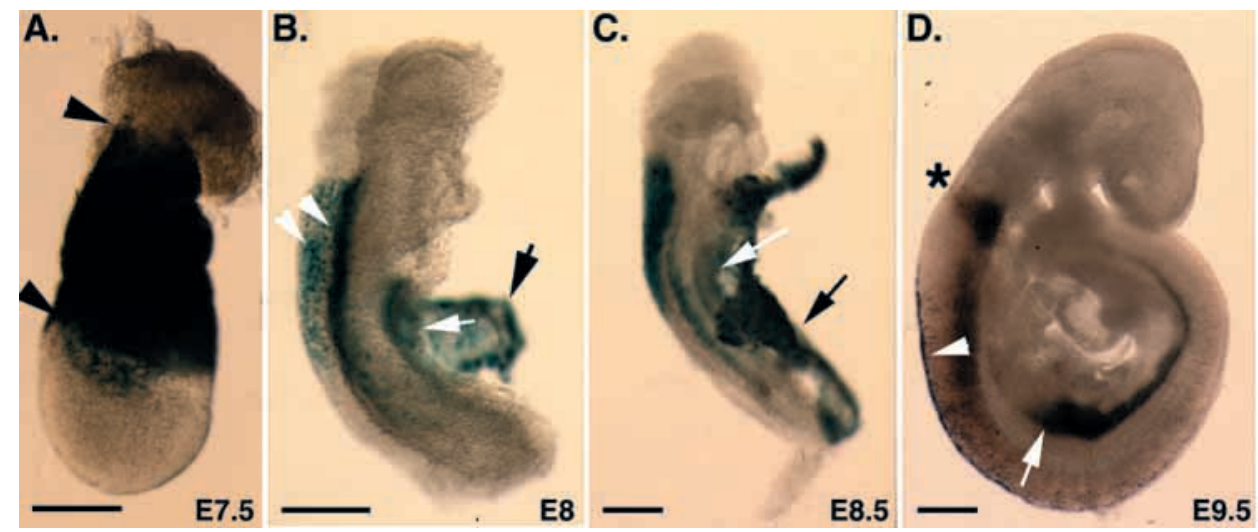

Fig. 2. Expression pattern of $v H N F 1$ at early stages of development as revealed by $\beta$-galactosidase activity. (A) E7.5 embryo; (B) E8 embryo; (C) E8.5 embryo; (D) E9.5 embryo. All embryos are heterozygous. Orientation: (A) ectoplacental cone on top and embryo on bottom; (B-D) head on top, back on the left. (A) Arrowheads: boundaries between embryonic and extraembryonic visceral endoderms; (B,C) black arrows, remainder of the yolk sac; white arrowheads, neural folds; white arrows, gut. (D) Star indicates the position of the otic vesicle; white arrowhead, roof plate staining; white arrow, anterior boundary of the gut staining. Scale bars: $250 \mu \mathrm{m}$ on A and D, $500 \mu \mathrm{m}$ on B and C.

$\mathrm{X}$-gal staining on chimeric embryos obtained from a second independent $\mathrm{vHNF} 1 /$ lac $Z$ clone.

\section{vHNF1 inactivation results in early embryonic lethality}

$\mathrm{vHNF}^{+/-}$mice are normal and fertile. They were crossed together and the resulting litters were genotyped by PCR. No $\mathrm{vHNF}^{-1-}$ mice were born (Table 1). Therefore, litters from heterozygotes were collected at different gestation times to investigate the timing of the embryonic lethality. At E6.5, $\mathrm{vHNF}^{-1-}$ embryos were normal and not distinguishable from their littermates (data not shown). Live $\mathrm{vHNF}^{-/-}$embryos were not found after E7.5 (Table 1). In the litters collected later than E8.5, only resorbed tissue could be genotyped as homozygous. At E7.5, vHNF1 ${ }^{-1}$ embryos were identified by PCR (Fig. 1C). They all presented a severe growth retardation when compared to their $\mathrm{vHNF} 1^{+/+}$and $\mathrm{vHNF} 1^{+/-}$littermates (Fig. 3). Morphological analysis of $\mathrm{vHNF}^{-/-}$embryos revealed in all cases a disorganization of the embryonic and extraembryonic tissues, despite some variations in the severity of the phenotype (Fig. 4). On sections of E7.5 heterozygous embryos, two territories in the visceral endoderm are morphologically distinct: the extraembryonic visceral

Table 1. Viability of $\mathrm{vHNF}^{-/}$embryos

\begin{tabular}{lcccccc}
\hline Age & $\begin{array}{c}\text { Number of } \\
\text { litters }\end{array}$ & \multicolumn{2}{c}{ Genotype of embryos } & & Number \\
\cline { 3 - 5 } & $+/+$ & $+/-$ & $-/-$ & & N.D. & $\begin{array}{c}\text { Nof pups } \\
\text { of }\end{array}$ \\
\hline Week 2 & 12 & 35 & 65 & 0 & & 100 \\
E10.5 & 4 & 5 & 15 & $(1)$ & 2 & 23 \\
E8.5 & 7 & 11 & 25 & $(10)$ & 11 & 57 \\
E7.5 & 6 & 14 & 23 & 7 & 10 & 54
\end{tabular}

PCR analysis of the litters from $\mathrm{vHNF} 1^{+/-}$intercrosses.

DNA was isolated from embryos between E7.5 and E10.5 and from 2week-old mice (Week 2). It was analyzed by PCR using the three primers featured on Fig. 1.

In parentheses are indicated the number of resorbed tissues genotyped as $\mathrm{vHNF}^{-1-}$.

N.D. (not determined) marks the number of embryos or resorbed tissues that could not be genotyped. endoderm composed of columnar epithelial cells is stained by $\mathrm{X}$-gal, whereas the epithelial layer surrounding the gastrulating embryo is squamous and negative for this staining (Fig. 4A). In contrast, the $\mathrm{vHNF}^{-/-}$embryos present a lack of development of the embryonic tissues (Fig. 4B,C). Most of them were highly degenerated and disorganized. They comprised a mass of undifferentiated cells, some of them positive for the X-gal staining, and were surrounded by trophoblastic tissues (Fig. 4C). Some embryos were more developed and underwent cavitation. However, the embryonic tissue was reduced and presented no sign of gastrulation. No clear regionalization of the visceral endoderm was observed in these embryos (Fig. 4B). Indeed, the visceral endoderm was uniformly composed of cuboidal epithelial cells, some expressing the lac $Z$ gene even at the distal pole of the embryos (Fig. 4B). This morphology was reminiscent of visceral endoderm from a E6.5 embryo. The defects in distinct visceral endoderm specialization led us to investigate the role of $v H N F 1$ in this differentiation pathway.

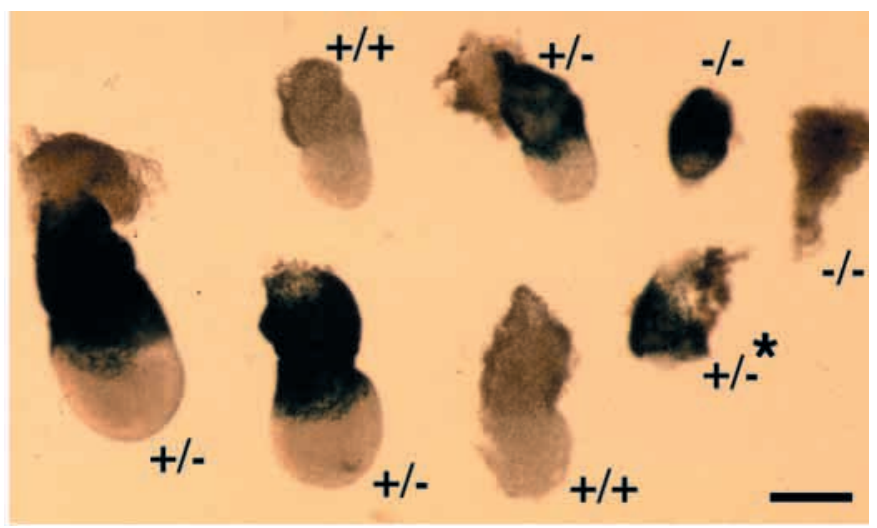

Fig. 3. A representative litter obtained from a vHNF1 ${ }^{+/-}$intercross, stained for vHNF1/lacZ activity. vHNF1 ${ }^{-/}$embryos present a severe growth retardation and disorganized tissues at E7.5. Genotypes obtained by PCR are indicated next to the embryos. *, broken vHNF1+/- embryo. Scale bar, $300 \mu \mathrm{m}$. 

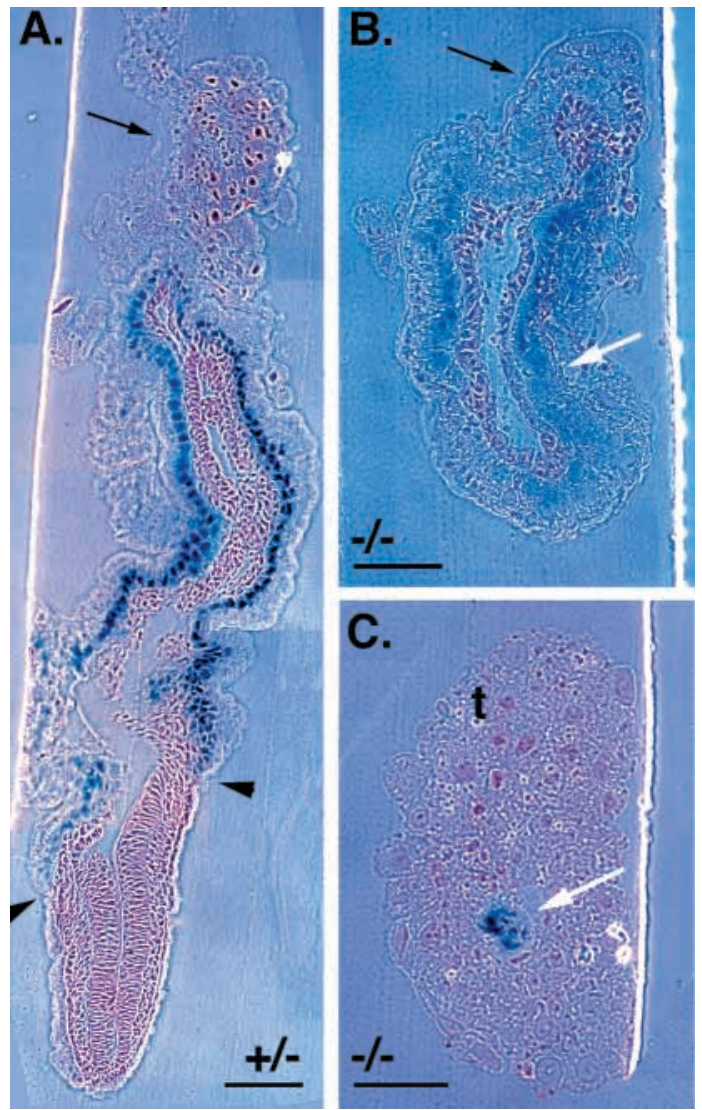

Fig. 4. Sections of (A) vHNF1 $1^{+/-}$and $(\mathrm{B}, \mathrm{C}) \mathrm{vHNF} 1^{-/-}$E7.5 embryos after X-gal staining. Black arrows, ectoplacental cone; black arrowheads, embryonic/extraembryonic boundary of the visceral endoderm; white arrows in B, cuboidal visceral endoderm; white arrows in $\mathrm{C}, \mathrm{vHNF} 1 /$ lacZ-positive cells; $\mathrm{t}$, trophoblastic tissue. Longitudinal sections. Scale bars, $120 \mu \mathrm{m}$.

\section{$v H N F 1$ inactivation affects in vitro differentiation of ES cells into visceral endoderm}

ES cells differentiation provides a good model to study visceral endoderm formation. Indeed, when cultured in suspension, clumps of ES cells form complex vesicles called embryoid bodies (EB). These vesicles contain both ectoderm and visceral endoderm. Their development in culture can be considered as equivalent to the early stages of embryogenesis (Keller, 1995). As one of the genes activated during this process is $v H N F 1$ (Abe et al., 1996), we have compared the formation of EB generated from $\mathrm{vHNF} 1^{+/+}, \mathrm{vHNF} 1^{+/-}$and $\mathrm{vHNF} 1^{-/-} \mathrm{ES}$ cells. Cells were cultured in suspension for 14 days, a time by which visceral endoderm differentiation should be completed (Abe et al., 1996). The resulting EB were analyzed for both their morphology and the expression of various differentiation markers (Fig. 5). Experiments were repeated several times with independently isolated clones. Embryoid bodies obtained from $\mathrm{vHNF}^{-/-}$ES cells were always smaller than the control (+/-) EB (Fig. 5A). They never formed expanded vesicles containing a tissue equivalent to yolk sac. However, both $\mathrm{vHNF}^{+/-}$and $\mathrm{vHNF}^{-1-}$ EB contain endodermal cells as detected by SJA lectin staining (Sophora japonica agglutinin, see Soudais et al., 1995) (data not shown).
A.

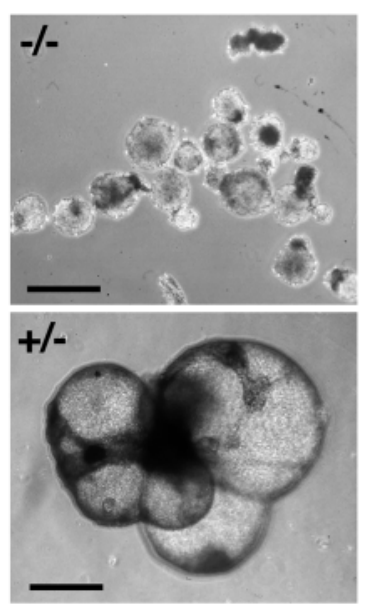

B.

TFN

TTR

AFP

Apo A I

Apo A IV

GATA-4

HNF4

HNF1

HNF3 $\alpha$

HNF3 $\beta$

HNF3 $\gamma$

BMP-6

HPRT+

HPRT-

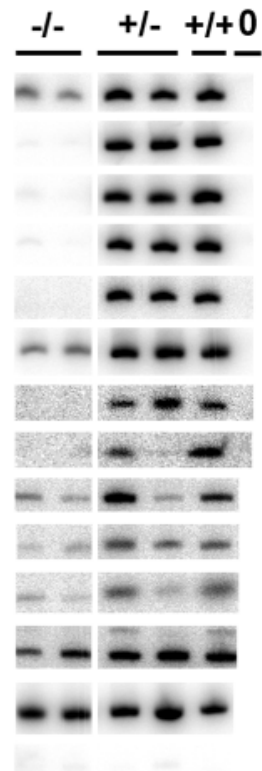

Fig. 5. $v H N F 1$ inactivation alters the ES cell differentiation into visceral endoderm. (A) 14-day-old embryoid bodies from either $\mathrm{vHNF}^{-/-}$or $\mathrm{vHNF} 1^{+/-}$cells. Scale bar, $300 \mu \mathrm{m}$. (B) RT-PCR analysis of endodermal markers of total RNAs from $\mathrm{vHNF}^{-/-}$, $\mathrm{vHNF} 1^{+/-}$or $\mathrm{vHNF} 1^{+/+}$embryoid bodies. Genotypes are indicated on top. 0, PCR control - no DNA. HPRT primers were used as a normalizing standard for the RT samples $(H P R T+)$ and as a reverse transcription control (HPRT-, control reaction without reverse transcriptase). TFN, Transferrin; TTR, Transthyretin; AFP, Alpha Fetoprotein; ApoAI, Apolipoprotein AI; ApoAIV, Apolipoprotein AIV; BMP-6, Bone Morphogenetic Protein 6.

To examine the expression of endodermal markers, total RNAs were prepared from EB and RT-PCR analysis performed. Primers for the HPRT gene were used as controls (Fig. 5B). Early endoderm markers like GATA-4 (Fig. 5B) and GATA-6 (not shown) were expressed in $\mathrm{vHNF} 1^{-1-} \mathrm{EB}$ as in controls, despite a decrease in their level. On the contrary, late endodermal markers, such as alphafetoprotein (AFP), transthyretin (TTR) and apolipoproteins, were not expressed in the $\mathrm{vHNF}^{-/-} \mathrm{EB}$. Remarkably, expression of the transcription factors $\mathrm{HNF} 4 \alpha$ and HNF1 was strongly reduced, in contrast to the expression levels of the HNF3 genes, which were approximately equivalent to those of the $\mathrm{vHNF}^{+/+}$and $\mathrm{vHNF}^{+/-}$samples. The expression of signaling molecules that are expressed at the equivalent stage of embryonic development was also examined: no variations were observed for the two secreted factors BMP-6 (Fig. 5B) and BMP-4 (not shown).

These results suggest a block of the differentiation of the vHNF1 $1^{-I-}$ ES cells into visceral endoderm. GATA factor expression and positive SJA staining of $\mathrm{vHNF}^{-/-} \mathrm{EB}$ demonstrate that the first steps of visceral endoderm differentiation still occur in the absence of $v H N F 1$. However, this process is not completed as shown by the lack of expression of the late markers.

\section{$v H N F 1$ is essential for in vivo differentiation of the visceral endoderm}

We next analyzed the expression of several endodermal 


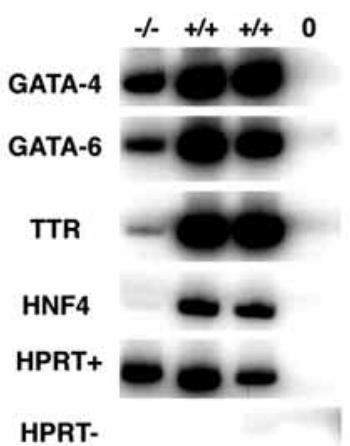

Fig. 6. Visceral endoderm differentiation is impaired in vHNF1 ${ }^{-1-}$ embryos. RT-PCR analysis of endodermal markers was performed on E7.5 vHNF1 ${ }^{-1-}$ and $\mathrm{vHNF} 1^{+/+}$embryos. Material for $\mathrm{vHNF} 1^{-1-}$ embryos was pooled from a set of four embryos, $\mathrm{vHNF} 1^{+/+}$were analyzed individually. The controls and the procedure are the same as in Fig. 5.

markers in E7.5 vHNF1 $1^{+/+}$and $\mathrm{vHNF} 1^{-/-}$embryos. Due to the small size of mutant embryos, genotyping was achieved on DNA from ectoplacental cone and RT-PCR was then performed either on a wild-type embryo or a pool of four mutant embryos. As previously, HPRT primers were used to normalize the samples. $v H N F 1$ inactivation in vivo results in effects similar to those observed in vitro: both GATA-4 and GATA- 6 are expressed despite a slight decrease in their levels; in contrast, the levels of the HNF4 and transthyretin genes are strongly reduced (Fig. 6).

Both in vitro and in vivo analysis revealed a requirement for vHNF1 expression during visceral endoderm differentiation. This defect in one of the first extraembryonic tissues could explain the growth retardation and abnormal morphology of the mutant embryos. To address this issue, rescue experiments were attempted by providing wild-type extraembryonic annexes to mutant embryos. This should also permit the examination of additional $v H N F 1$ functions during embryonic development.

\section{Tetraploid aggregation partially rescues $v H N F 1$ inactivation}

Wild-type visceral endoderm can be provided to a mutant embryo by aggregating tetraploid morulae with a clump of ES cells. The resulting embryos are composed of two distinct compartments: the extraembryonic tissue is wild type and tetraploid, whereas the embryo itself derives from the diploid ES cells (Rossant and Spence, 1998). This experiment permits to investigate the effect of wild-type visceral endoderm on the viability of $\mathrm{vHNF} 1^{-/}$embryos. In addition, this should allow us to examine the effect of $v H N F 1$ inactivation in other tissues.

Aggregation experiments were performed with two independent $\mathrm{vHNF}^{-/-} \mathrm{ES}$ clones, as well as with $\mathrm{vHNF}^{+/-}$ cells as a control. Embryos obtained with control cells were perfectly normal at E9.5 (not shown). Embryos resulting from the aggregation of wild-type tetraploid morula with $\mathrm{vHNF} 1^{-1-}$ cells (denoted +/+::-/-) were viable up to E10. At E8.5 these embryos were not distinguishable from vHNF1 ${ }^{+/-}$embryos in terms of both their size and morphology. At E9.5, the rescued embryos still presented a normal size for this embryonic stage (Fig. 7A,B). These results demonstrate that wild-type visceral endoderm can efficiently rescue both the early lethality and the growth retardation due to the vHNF1 mutation. It also showed that $\mathrm{vHNF} 1^{-/}$epiblast can normally develop after implantation and undergo gastrulation. However, morphological examination of the E9.5 +/+::-/- embryos revealed some interesting abnormalities. The embryos did not turn, they were rather short

and their general appearance corresponded more to a E8.5 embryo (Fig. 7C). The neural tube remained open and exhibited expanded tissue on both neural folds; often, this overgrowth was associated with several oedemas on the neural folds and on the forebrain vesicles. Despite being wild type, the endodermal layer of the yolk sac was oversized and ruffled (not shown). An enlarged allantois and a distended pericardia were also observed in a majority of $+/+:$ - $/-$ embryos (Fig. 7C).

$\mathrm{X}$-gal staining of the $+/+::-/-$ embryos revealed an additional abnormality. As it was reported for the heterozygotes, $\beta$-galactosidase activity was detected in both the gut and the neural folds. Still, vHNF1/lacZ expression in the neural tissue was not restricted, either laterally and ventrally, as it should be at E9.5. This expression was even expanded (Fig. 7B,C). In addition, the staining remained uniform at E9.5 all along the neural tube as if no anteroposterior regionalization of $\mathrm{vHNF} 1 /$ lacZ expression was accomplished in the absence of vHNF1 protein.

\section{vHNF1-/- cells contribute differentially to chimeric embryo tissues}

The morphological abnormalities exhibited by the rescued vHNF1 $1^{-/-}$embryos suggested a requirement for the expression of this gene during morphogenesis, in addition to its essential function in visceral endoderm. To determine if the activity of the gene was cell-autonomously required or not in embryonic tissues, the behavior of the vHNF1 $1^{-/-} \mathrm{ES}$ cells in a wild-type environment was examined by injecting 7 to 8 cells into wildtype blastocysts. The resulting chimeras were collected between E9.5 and E 11.5. They all presented a normal morphology (Fig. 7D-F). After X-gal staining, vHNF1/lacZpositive cells could be detected in both the neural tube and the mesonephros (Fig. 7E,F). The neural tube was closed and the mesonephros was normal.

On the contrary, vHNF1 $1^{-/-}$blue cells were observed in the gut in only one out of eight chimeric embryos. In this case, the stained cells were clustered in spots and some were detected at a position more anterior than expected (not shown). In contrast, in all three chimeras obtained by the injection of vHNF1 ${ }^{+/-}$ES cells, we observed a strong and uniform staining in the gut, similar to that observed for $F_{1}$ heterozygous embryos. So, these results suggest that vHNF1 ${ }^{-/-}$cells present a strongly reduced capacity to contribute to gut formation.

\section{DISCUSSION}

Transcription factors interact in a functional network to specify cell differentiation. We have been interested in analyzing the function of the vHNF1 homeoprotein by inactivating the corresponding gene in the mouse. From in vivo and in vitro studies, we demonstrate that $v H N F 1$ is required for visceral endoderm differentiation as well as for morphogenesis and we identify potential target genes of $v H N F 1$ in the visceral endoderm.

\section{Dynamic expression of vHNF1 during early embryogenesis}

The introduction of an NLS-lacZ reporter gene at the initiation codon of $v H N F 1$ has provided us with an easy visualization of 
$v H N F 1$ expression by $\mathrm{X}$-gal staining. $\beta$-galactosidase activity was first detected in the extraembryonic part of the visceral endoderm at E7.5. At the 2-somite stage, it was also detected in the embryo proper, first in the neural folds then in the invaginating gut. This result corroborates previous data obtained by in situ hybridization, where $v H N F 1$ mRNA was detected in the visceral endoderm at E6.5 (Cereghini et al., 1992). An interesting feature of $v H N F 1$ expression at E9.5 is the sharp anterior boundary of the gut expression domain. The regionalization of the gut is established by the spatially restricted expression of several genes in the mesoderm during epithelium-mesenchyme interactions (Roberts et al., 1998). The mechanisms of endoderm patterning are less understood, but they certainly imply the differential expression of regulatory genes. Considering this model, the sharp anterior boundary observed for vHNF1/lacZ expression suggests that $v H N F 1$ could contribute to the determination of territories in the gut in combination with other transcription factors. In particular it could play a role in the specification of the liver and pancreatic primordia. This issue will be the subject of future studies using the conditional inactivation of the gene.

The expression pattern of $v H N F 1$, as depicted by $\mathrm{X}$-gal staining, and the phenotype of the tetraploid-rescued mutant embryos strongly argue for $v H N F 1$ playing a role in neural tube formation. This function was unexpected. Indeed, the expression of $v H N F 1$ in the neural tube of the mouse has not been described previously except as a transient signal in the neuroepithelium of the murine embryo. However, it should be recalled that $v H N F 1$ expression has been reported in the neural tube of two other vertebrates, Xenopus (Demartis et al., 1994) and zebrafish (Thisse and Thisse, 1998).

\section{vHNF1 expression is critical for visceral endoderm differentiation}

As mentioned above, $v H N F 1$ is specifically expressed in the extraembryonic territory of the visceral endoderm at E7.5. Combined studies of the mutant embryos and ES cell differentiation have shown that visceral endoderm formation is strongly impaired in the absence of $v H N F 1$. These results are the first evidence for an essential role for $v H N F 1$ in controlling this process. In addition, wild-type visceral endoderm provided by tetraploid aggregation was shown to rescue the lethality and growth defect of the mutant embryos. This approach allowed us to bypass the lethality up to E9.5.

The differentiation of the visceral endoderm is a crucial event for the mammalian embryogenesis. The discovery of the organizer properties of this tissue has recently awakened much interest (Beddington and Robertson, 1998). But the visceral endoderm plays also a major role during the periimplantation development in supporting embryonic metabolism. The knowledge concerning these functions remains fragmentary. Still, it has been established that it is a multistep process in which the HNF4 factor seems to play an important role. It is known that numerous secreted proteins are produced by this tissue such as serum proteins (AFP, TTR) or apolipoproteins (Meehan et al., 1984) and that their production is dependent upon HNF4 expression (Duncan et al., 1997).

Several mutations like Smad4/Dpc4 (Sirard et al., 1998), evx1 (Spyropoulos and Capecchi, 1994), Nf2 (McClatchey et al., 1997) or GATA-6 (Morrisey et al., 1998) were characterized that result in the failure of development due to a defect of visceral endoderm functions. A strong similarity exists between the Smad4/Dpc4, GATA-6 and vHNF1 phenotypes. These mutations lead to embryonic lethality at E77.5 and to a severe growth retardation. A disorganization of the visceral endoderm has been described and the lethality occurs shortly after the initiation of their expression in this tissue. Also, the mutation of each of these three genes results in a lack of HNF4 expression.

Further insights into the relationship between regulators during visceral endoderm differentiation have come from the study of ES cells. When cultured in suspension, they develop following a program analogous to that occurring in the embryo. A regulatory network involved in this process has been recently proposed by Duncan and co-workers (1998). It organizes some of the $H N F$ genes hierarchically: for instance, $H N F 3 \beta$ regulates both $H N F 3 \alpha$ and $H N F 4 \alpha$ expression in the visceral endoderm. Morrisey and co-workers (1998) have reported similar observations concerning GATA- 6 that would directly regulate HNF4 expression. Our studies allow us to place $v H N F 1$ in this pathway. Although some endoderm is formed from the ES cells in the absence of $v H N F 1$ as demonstrated by the expression of the GATA factors and the positive staining for SJA lectin, their differentiation remains incomplete as they lack late endodermal markers. The genes examined in the embryos were affected both in vitro and in vivo in the absence of $v H N F 1$. These results are the first evidence for an important role of $v H N F 1$ during visceral endoderm differentiation.

A model for visceral endoderm differentiation is shown in Fig. 8. GATA-6 and GATA-4 are required for the onset of visceral endoderm differentiation right after the specification of this tissue, but the completion of this process requires the additional expression of both $H N F 3$ and $v H N F 1$. As the expressions of the $H N F 3$ and GATA genes are not affected by $v H N F 1$ inactivation, we can propose, in accordance with the results of Duncan (1998) and Morrisey (1998), that $H N F 3 \beta$, GATA-6 and $v H N F 1$ are acting through separate pathways converging on $H N F 4 \alpha$ (Fig. 8).

Furthermore, as the promoters for serum proteins like TTR contain HNF4- and vHNF1/HNF1-binding sites (Xanthopoulos et al., 1991), both these transcription factors could be essential for their expression. The combined action of vHNF1 and HNF4 would switch on the expression of the target genes. It is worth recalling that $v H N F 1$ is expressed in the absence of $H N F 4 \alpha$ (Duncan et al., 1997). As a binding site for vHNF1 is present in the $H N F 4 \alpha$ promoter (Taraviras et al., 1994), vHNF1 could lie just upstream of HNF4. Still, the early lethality observed at $\mathrm{E} 7.5$ for the $\mathrm{HNF}^{-/-}$embryos contrasts with the phenotype of the HNF4 ${ }^{-/-}$embryos that survive up to E10.5 and display a normal morphology (Chen et al., 1994). This confirms our conclusions that vHNF1 plays a role in the regionalization and structural specification of the extraembryonic visceral endoderm.

In addition, in embryoid bodies, HNFl expression is not affected by HNF4 inactivation (Duncan et al., 1997), but is downregulated in the absence of $v H N F 1$. This result suggests a direct requirement for $v H N F 1$ in the visceral endoderm to activate $H N F 1$ expression. This hierarchy of transcription factors differs from the network reported for the hepatic model. Indeed, in hepatocytes, $H N F 1$ expression has been described as strictly dependent upon that of $H N F 4$, whereas both $H N F 1$ and HNF4 seem to be independent of $v H N F 1$ (reviewed in 

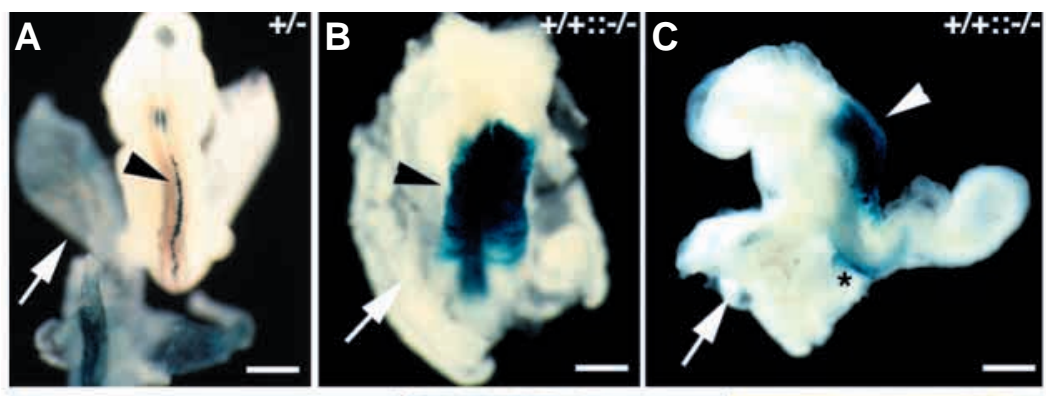

Fig. 7. vHNF1 might play multiple roles during the embryonic morphogenesis. (A-C) Wild-type visceral endoderm is able to rescue partially the vHNF1 mutation. (A) E9.5 vHNF1 $1^{+/-}$embryo. (B,C) E9.5 embryos resulting from aggregations of $\mathrm{vHNF} 1^{+/+}$tetraploid embryos with vHNF1 $1^{-l-}$ ES cells. All three embryos were stained for $\beta$ galactosidase activity. Note the expanded neural tube staining for $\mathrm{vHNF} 1 /$ lac $Z$ in the rescued embryos (arrowheads, compare A to B and C). The wild-type yolk sacs (white arrows) are negative for $\beta$-galactosidase activity. Black star in $\mathrm{C}$, gut. Orientation: $(\mathrm{A}, \mathrm{B})$ dorsal D view, anterior on top; (C) lateral view, anterior left. Scale bar: $600 \mu \mathrm{m}$. (D-F) vHNF1 ${ }^{-/-}$cells can contribute to normal neural tube and mesonephros. Chimeras were obtained after injection of $\mathrm{vHNF} 1^{-/-}$cells into wild-type blastocysts; they were stained for $\beta$-galactosidase activity. (D) E9.5 chimera; (E) E10.5 chimera; (F) E11.5 chimera after abdominal wall removal. No blue cells were detected in the gut of these embryos. Black arrowheads, mesonephros; white and black arrows, neural tube; black square, hindbrain staining. Scale bars: (D) $200 \mu \mathrm{m}$; (E) $400 \mu \mathrm{m}$; (F) $100 \mu \mathrm{m}$.

Tronche et al., 1994). Hence, cell differentiation would not only involve the combined expression of transcription factors, but these factors would also be hierarchically organized into different networks depending on the differentiation program.

\section{Multiple developmental requirements for vHNF1}

The tetraploid aggregation allowed us to provide mutant embryos with wild-type extraembryonic annexes. We were able to show that the wild-type visceral endoderm can rescue both the early lethality and the growth defect of the vHNF1-/epiblast. Furthermore, it leads to a normal development including gastrulation, up to E9. We can conclude that the embryonic lethality of the $\mathrm{vHNF} 1^{-/-}$embryos at E7.5 is not caused by any epiblast defect, but is the consequence of impaired visceral endoderm functions. Normal development was observed up to E9, then morphological abnormalities appeared at the two sites of $v H N F 1$ expression, the neural tube and the gut. The neural tube remained completely open and the gut failed to close and/or invaginate. Additionally, the embryos

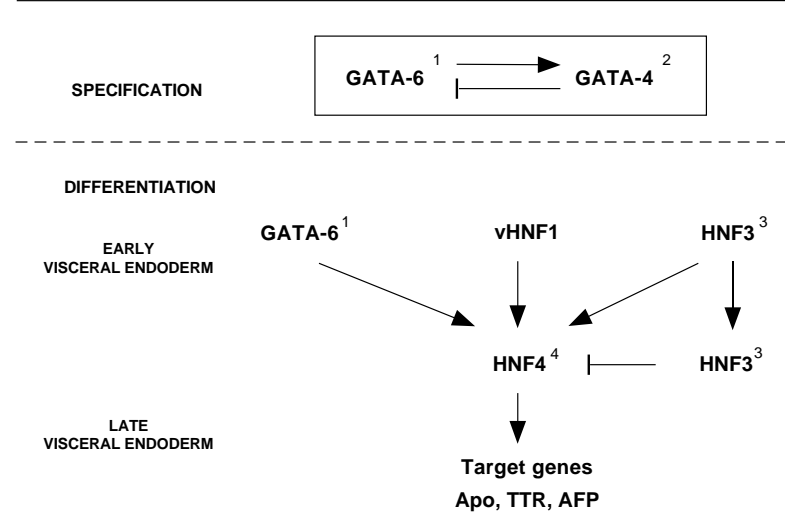

1: Morrisey et al, $1998 ;{ }^{2}$ : Soudais et al, $1995 ;{ }^{3}$ : Duncan et al, $1998{ }^{4}$ : Duncan et al, 1997

Fig. 8. A regulatory network of transcription factors involved in visceral endoderm differentation. failed to turn and the short appearance of their bodies suggested a possible truncation of the posterior part. These embryos looked more like E8.5 than E9.5/10 stages. This phenotype suggested a block occurring during morphogenesis.

The vHNF1+/+::-/- embryos present striking similarities in their phenotypes with four knock-outs: Fgf receptorl (Deng et al., 1994; Yamaguchi et al., 1994), $\alpha 5$ integrin (Yang et al., 1993), N-cadherin (Radice et al., 1997) and fibronectin (George et al., 1993). These mutations result, to different extents, in the association of the following defects: kinking of the neural tube, ruffling of the visceral endoderm, swelling of the pericardium and overgrowth of the allantois. These similarities suggest that signaling pathways involving secreted factors or cell adhesion might be impaired in the vHNF1+/+::-/- embryos.

To study the effect of the vHNF1 mutation in a wild-type environment, we produced chimeric embryos by injecting ES cells into wild-type blastocysts. Monitoring the presence of $\mathrm{vHNF}^{-l-}$ cells by $\mathrm{X}$-gal staining of the tissues normally expressing $v H N F 1$ should allow us to determine if the effect of the mutation is cell-autonomous or not. The resulting chimeras displayed a normal morphology at E9.5-11.5. Hence, vHNF $1^{-/}$cells could contribute to both the neural tube and the mesonephros in a wild-type context. In contrast, a majority of the chimeras lacked blue cells in the gut, indicating a possible exclusion of the $\mathrm{vHNF} 1^{-/}$cells from the gut or a lower ability to colonize this tissue. This analysis suggests that $v H N F 1$ could act through different pathways depending on the tissues where it is expressed. The absence of $v H N F 1$ could be deleterious for cells in the gut; but not in the neural tube where the vHNF1 mutation would be complemented by the surrounding wildtype cells.

In conclusion, the null mutation of the murine $v H N F 1$ gene has allowed us to characterize three early and specific functions of $v H N F 1$ during embryogenesis. We have shown that $v H N F 1$ expression is necessary for visceral endoderm differentiation and we present evidence for the involvement of $v H N F 1$ during morphogenesis, both in the neural tube and in the gut.

The embryonic lethality has hampered the study of the later 
functions of the gene in the polarized epithelia where $v H N F 1$ is specifically expressed. To analyze these possible functions during late embryogenesis or in adult tissues, we will pursue the conditional inactivation of the gene using the Cre/lox system. This study will be of a particular interest in the pancreas as two human vHNF1 mutations have been recently characterized that are associated with a type II diabetes (Horikawa et al., 1997; Nishigori et al., 1998).

We thank C. Kress for providing the CK35 ES cells, P. Brulet and $\mathrm{H}$. Le Mouellic for the $l a c Z$ cassette and the mouse genomic library, J. C. Benichou and C. Cimper for helpful advice in sectioning, A. Doyen and B. Bourachot for technical advice, M. Pontoglio and D. Lallemand for help in the production of the vHNF1 antiserum, F. Tronche for the vector containing the loxP sites. We are grateful to J. Weitzman, A. Yeivin and A. El Amraoui for critical reading of the manuscript. C. C. was an Allocataire Moniteur Normalien at the Paris XI University. This work was supported by grants from the EEC Biotechnology program, the ARC and the LNFCC.

\section{REFERENCES}

Abe, K., Niwa, H., Iwase, K., Takiguchi, M., Mori, M., Abe, S. I., Abe, K. and Yamamura, K. I. (1996). Endoderm-specific gene expression in embryonic stem cells differentiated to embryoid bodies. Exp. Cell Res. 229, 27-34.

Ang, S. L. and Rossant, J. (1994). HNF-3 beta is essential for node and notochord formation in mouse development. Cell 78, 561-574.

Beddington, R. S. and Robertson, E. J. (1998). Anterior patterning in mouse. Trends Genet. 14, 277-284.

Blumenfeld, M., Maury, M., Chouard, T., Yaniv, M. and Condamine, H. (1991). Hepatic nuclear factor 1 (HNF1) shows a wider distribution than products of its known target genes in developing mouse. Development 113, 589-599.

Cereghini, S., Ott, M. O., Power, S. and Maury, M. (1992). Expression patterns of vHNF1 and HNF1 homeoproteins in early postimplantation embryos suggest distinct and sequential developmental roles. Development 116, 783-797.

Chen, W. S., Manova, K., Weinstein, D. C., Duncan, S. A., Plump, A. S., Prezioso, V. R., Bachvarova, R. F. and Darnell, J. E. J. (1994). Disruption of the HNF-4 gene, expressed in visceral endoderm, leads to cell death in embryonic ectoderm and impaired gastrulation of mouse embryos. Genes Dev. 8, 2466-2477.

Copp, A. J. (1995). Death before birth: clues from gene knockouts and mutations. Trends Genet. 11, 87-93.

Demartis, A., Maffei, M., Vignali, R., Barsacchi, G. and De Simone, V. (1994). Cloning and developmental expression of LFB3/HNF1 beta transcription factor in Xenopus laevis. Mech. Dev. 47, 19-28.

Deng, C. X., Wynshaw-Boris, A., Shen, M. M., Daugherty, C., Ornitz, D. M. and Leder, P. (1994). Murine FGFR-1 is required for early postimplantation growth and axial organization. Genes Dev. 8, 3045-3057.

Dufort, D., Schwartz, L., Harpal, K. and Rossant, J. (1998). The transcription factor HNF3beta is required in visceral endoderm for normal primitive streak morphogenesis. Development 125, 3015-3025.

Duncan, S. A., Manova, K., Chen, W. S., Hoodless, P., Weinstein, D. C., Bachvarova, R. F. and Darnell, J. E. J. (1994). Expression of transcription factor HNF-4 in the extraembryonic endoderm, gut, and nephrogenic tissue of the developing mouse embryo: HNF-4 is a marker for primary endoderm in the implanting blastocyst. Proc. Natl. Acad. Sci. USA 91, 7598-7602.

Duncan, S. A., Nagy, A. and Chan, W. (1997). Murine gastrulation requires HNF-4 regulated gene expression in the visceral endoderm: tetraploid rescue of Hnf-4(-/-) embryos. Development 124, 279-287.

Duncan, S. A., Navas, M. A., Dufort, D., Rossant, J. and Stoffel, M. (1998). Regulation of a transcription factor network required for differentiation and metabolism. Science 281, 692-695.

George, E. L., Georges-Labouesse, E. N., Patel-King, R. S., Rayburn, H. and Hynes, R. O. (1993). Defects in mesoderm, neural tube and vascular development in mouse embryos lacking fibronectin. Development 119, 1079-1091.
Gu, H., Zhou, Y. R. and Rajewsky, K. (1993). Independent control of immunoglobulin switch at individual switch regions evidenced through the Cre-loxP-mediated gene targeting. Cell 73, 1155-1164.

Guillemot, F., Nagy, A., Auerbach, A., Rossant, J. and Joyner, A. L. (1994). Essential role of Mash-2 in extraembryonic development. Nature 371, 333 336.

Horikawa, Y., Iwasaki, N., Hara, M., Furuta, H., Hinokio, Y., Cockburn, B. N., Lindner, T., Yamagata, K., Ogata, M., Tomonaga, O. et al. (1997). Mutation in hepatocyte nuclear factor-1 beta gene (TCF2) associated with MODY. Nature Genet. 17, 384-385.

Keller, G. M. (1995). In vitro differentiation of embryonic stem cells. Curr. Opin. Cell Biol 7, 862-869.

Koopman, P. (1993). Analysis of gene expression by reverse transcriptasepolymerase chain reaction. In Essential Developmental Biology: a Practical Approach, (ed. C. D. Stern and P. W. H. Holland), pp. 231-242. Oxford: IRL Press Limited.

Kress, C., Vandormael-Pournin, S., Baldacci, P., Cohen-Tannoudji, M. and Babinet, C. (1998). Nonpermissiveness for mouse embryonic stem (ES) cell derivation circumvented by a single backcross to $129 / \mathrm{Sv}$ strain: establishment of ES cell lines bearing the $O m^{\mathrm{d}}$ conditional lethal mutation. Mammalian Genome 9, 998-1001.

McClatchey, A. I., Saotome, I., Ramesh, V., Gusella, J. F. and Jacks, T. (1997). The Nf2 tumor suppressor gene product is essential for extraembryonic development immediately prior to gastrulation. Genes Dev. 11, 1253-1265.

Meehan, R. R., Barlow, D. P., Hill, R. E., Hogan, B. L. M. and Hastie, N. D. (1984). Pattern of serum protein gene expression in mouse visceral yolk sac and foetal liver. EMBO J. 3, 1881-1885.

Monaghan, A. P., Kaestner, K. H., Grau, E. and Schutz, G. (1993). Postimplantation expression patterns indicate a role for the mouse forkhead/HNF-3 alpha, beta and gamma genes in determination of the definitive endoderm, chordamesoderm and neuroectoderm. Development 119, 567-578.

Morrisey, E. E., Tang, Z., Sigrist, K., Lu, M. M., Jiang, F., Ip, H. S. and Parmacek, M. S. (1998). GATA6 regulates HNF4 and is required for differentiation of visceral endoderm in the mouse embryo. Genes Dev. 12, 3579-3590.

Mortensen, R. M., Conner, D. A., Chao, S., Geisterfer-Lowrance, A. A. and Seidman, J. G. (1992). Production of homozygous mutant ES cells with a single targeting construct. Mol. Cell. Biol. 12, 2391-2395.

Nagy, A., Rossant, J., Nagy, R., Abramow-Newerly, W. and Roder, J. C. (1993). Derivation of completely cell culture-derived mice from earlypassage embryonic stem cells. Proc. Natl. Acad. Sci. USA 90, 8424-8428.

Nishigori, H., Yamada, S., Kohama, T., Tomura, H., Sho, K., Horikawa, Y., Bell, G. I., Takeuchi, T. and Takeda, J. (1998). Frameshift mutation, A263fsinsGG, in the hepatocyte nuclear factor-1beta gene associated with diabetes and renal dysfunction. Diabetes 47, 1354-1355.

Ott, M. O., Rey-Campos, J., Cereghini, S. and Yaniv, M. (1991). vHNF1 is expressed in epithelial cells of distinct embryonic origin during development and precedes HNF1 expression. Mech. Dev. 36, 47-58.

Pontoglio, M., Barra, J., Hadchouel, M., Doyen, A., Kress, C., Bach, J. P., Babinet, C. and Yaniv, M. (1996). Hepatocyte nuclear factor 1 inactivation results in hepatic dysfunction, phenylketonuria, and renal Fanconi syndrome. Cell 84, 575-585

Pontoglio, M., Sreenan, S., Roe, M., Pugh, W., Ostrega, D., Doyen, A., Pick, A. J., Baldwin, A., Velho, G., Froguel, P. et al. (1998). Defective insulin secretion in hepatocyte nuclear factor 1alpha-deficient mice. J. Clin. Invest. 101, 2215-2222.

Radice, G. L., Rayburn, H., Matsunami, H., Knudsen, K. A., Takeichi, M. and Hynes, R. O. (1997). Developmental defects in mouse embryos lacking N-cadherin. Dev. Biol. 181, 64-78.

Roberts, D. J., Smith, D. M., Goff, D. J. and Tabin, C. J. (1998). Epithelialmesenchymal signaling during the regionalization of the chick gut Development 125, 2791-2801.

Rossant, J. and Spence, A. (1998). Chimeras and mosaics in mouse mutant analysis. Trends Genet. 14, 358-363.

Rudnicki, M. A. and McBurney, M. W. (1987). Cell culture methods and induction of differentiation of embryonal carcinoma cell lines. In Teratocarcinomas and Embryonic Stem cells: a Practical Approach, (ed. E. J. Robertson), pp. 19-49. Oxford: IRL Press Limited.

Sirard, C., de la Pompa, J. L., Elia, A., Itie, A., Mirtsos, C., Cheung, A., Hahn, S., Wakeham, A., Schwartz, L., Kern, S. E. et al. (1998). The tumor suppressor gene Smad4/Dpc4 is required for gastrulation and later for anterior development of the mouse embryo. Genes Dev. 12, 107-119. 
Soudais, C., Bielinska, M., Heikinheimo, M., MacArthur, C. A., Narita, N., Saffitz, J. E., Simon, M. C., Leiden, J. M. and Wilson, D. B. (1995). Targeted mutagenesis of the transcription factor GATA-4 gene in mouse embryonic stem cells disrupts visceral endoderm differentiation in vitro. Development 121, 3877-3888.

Spyropoulos, D. D. and Capecchi, M. R. (1994). Targeted disruption of the even-skipped gene, evx1, causes early postimplantation lethality of the mouse conceptus. Genes Dev. 8, 1949-1961.

Taraviras, S., Monaghan, A. P., Schutz, G. and Kelsey, G. (1994). Characterization of the mouse HNF-4 gene and its expression during mouse embryogenesis. Mech. Dev. 48, 67-79.

Thisse, C. and Thisse, B. (1998). Antivin, a novel and divergent member of the TGFbeta superfamily, negatively regulates mesoderm induction. Development 126, 229-240.

Tronche, F. and Yaniv, M. (1992). HNF1, a homeodomain member of the hepatic transcription regulatory network. BioEssays 14, 579-587.

Tronche, F., Bach, I., Chouard, T., David-Wattine, B., Pontoglio, M., Ringeisen, F., Sourdive, D., Thépot, D. and Yaniv, M. (1994). Hepatocyte Nuclear factor 1 (HNF1) and liver gene expression. In Liver Gene Expression, (ed. F. Tronche and M. Yaniv), pp. 155-181. Austin: R. G. Landes Company.

Tybulewicz, V. L., Crawford, C. E., Jackson, P. K., Bronson, R. T. and
Mulligan, R. C. (1991). Neonatal lethality and lymphopenia in mice with a homozygous disruption of the c-abl proto-oncogene. Cell $\mathbf{6 5}, 1153$ 1163.

Weinstein, D. C., Ruiz i Altaba, A., Chen, W. S., Hoodless, P., Prezioso, V. R., Jessell, T. M. and Darnell, J. E. J. (1994). The winged-helix transcription factor HNF-3 beta is required for notochord development in the mouse embryo. Cell 78, 575-588.

Wiles, M. V. (1993). Embryonic stem cells differentiation in vitro. In Methods in Enzymology. vol. 225, pp 900-918. New York: Academic Press Inc.

Xanthopoulos, K. G., Prezioso, V. R., Chen, W. S., Sladek, F. M., Cortese, R. and Darnell, J. E. J. (1991). The different tissue transcription patterns of genes for HNF-1, C/EBP, HNF-3, and HNF-4, protein factors that govern liver-specific transcription. Proc. Natl. Acad. Sci. USA 88, 3807-3811.

Yamaguchi, T. P., Harpal, K., Henkemeyer, M. and Rossant, J. (1994). fgfr1 is required for embryonic growth and mesodermal patterning during mouse gastrulation. Genes Dev. 8, 3032-3044.

Yamamoto, H., Flannery, M. L., Kupriyanov, S., Pearce, J., McKercher, S. R., Henkel, G. W., Maki, R. A., Werb, Z. and Oshima, R. G. (1998). Defective trophoblast function in mice with a targeted mutation of Ets2. Genes Dev. 12, 1315-1326.

Yang, J. T., Rayburn, H. and Hynes, R. O. (1993). Embryonic mesodermal defects in $\alpha 5$ integrin-deficient mice. Development 119, 1093-1105. 